\title{
Tiger Image on Medicinal Plasters Serve as a Cue for Traditional Medicine Consumers
}

\author{
Zhao Liu $^{1,2}$ and Zhigang Jiang ${ }^{1,2,3^{*}}$ \\ ${ }^{1}$ Key Laboratory of Animal Ecology and Conservation Biology, Institute of Zoology, Chinese Academy of Sciences, Beijing, China \\ ${ }^{2}$ Graduate School of Chinese Academy of Sciences, Beijing, China \\ ${ }^{3}$ Endangered Species Scientific Commission of People, Republic of China, Beijing, China
}

*Corresponding author: Zhigang Jiang, Institute of Zoology, Chinese Academy of Sciences, Beijing, China, Tel: 86-10-64807268; E-mail: jiangzg@ioz.ac.cn

Received date: November 13, 2014; Accepted date: December 16, 2014; Published date: January 05, 2015

Copyright: $\odot 2015$ Liu Z, et al. This is an open-access article distributed under the terms of the Creative Commons Attribution License, which permits unrestricted use, distribution, and reproduction in any medium, provided the original author and source are credited.

\begin{abstract}
In the past, Musk and Tiger Bone Plaster (Tiger Bone Plaster for shorter) was one of most common nonprescription Traditional Chinese Medicine (TCM). Since 1993, China banned all trade in tiger bones and its derivatives in 1993. Musk deer were up-listed as Category I State Key Protected Wild Animal Species in China in 2002. The plaster manufactures changed the prescription of Tiger Bone Plaster and used synthetic musk and herb medicines and changed the name of Tiger Bone Plaster to "Musk and Bone Strengthening Plaster" but packages of some brands of the plasters still carry a tiger's image on it. Thus, consumers still consider the plasters as "Tiger Bone Plaster" because of the tiger image on the package. To investigate the consumer perception and behaviors of "Musk and Bone Strengthening Plaster", we surveyed 418 citizens in Beijing in 2014. We found that $43.78 \%$ of respondents alleged that they had used "Tiger Bone Plaster". When we inquired, almost all of respondents confirmed that the plasters they had used were "Musk and Bone Strengthening Plaster". Presumably, tiger's image on the plaster package produces a conditional stimulus to the consumers. Consumers preferred buying the plasters packed with tiger's image printed on the package. In fact, no people had really consumed Tiger Bone Plaster in this investigation. For the sake of protecting tigers, we argue the manufacturers to remove the tiger image from the "Musk and Bone Strengthening Plaster" according to the regulations of CITES.
\end{abstract}

Keywords: Conditional stimulus; Consumer perception and preference; "Tiger Bone Plaster"; Tiger's image

\section{Introduction}

Due to the habitat loss and fragmentation, coupled with depletion in prey and continued illegal poaching, the tiger habitat has shrunk by as much as $41 \%$ during the past 10 years and wild tigers occur in just $7 \%$ of their history range [1]. Currently, there are only about 3,000 wild tigers (Panthera tigris) in the world and the populations are still decreasing [2]. Illegal trade in tiger bones for traditional medicine and skins for ornamentation and collection are threats to wild tigers [2-5]. All tigers and other Asian big cat species are listed in Appendix I of the Convention on International Trade in Endangered Species of Wild Fauna and Flora (CITES), and that commercial international trade has been prohibited since 1975 [6]. Tigers should not be bred for trade in their parts and derivatives [7].

Musk and Tiger Bone Plaster (Tiger Bone Plaster for shorter) was one of most common non-prescription Traditional Chinese Medicine (TCM) for treating traumatic injure and rheumatism in TCM market. In 1993 China banned all trade of tiger bones and the plaster manufactures stopped using tiger bone and musk as ingredients of the Tiger Bone Plaster, which was renamed the "Musk and Bone Strengthening Plaster" [8]. Plaster manufactures instead used synthetic musk and herb medicines in the "Musk and Bone Strengthening Plaster" ever since. After the trade ban on Tiger Bone and Rhino Horn, a significant legal industry in tiger bones and medicines made from tiger bones was closed down in China $[3,9,10]$. Of 663 pharmacies and shops in 26 cities, only $3 \%$ claimed they supply of tiger bones [4].
Investigations on the medicine market and TCM producers showed that the trade in tiger bones had been effectively controlled [4,5,11]. A recent study on the TCM market indicated that the average presence of tiger bone stalls was only $0.8-1.4 \%$, and all the operators know about related tiger bans or regulations [12].

An investigation on the consumption of tiger products in China showed that $38 \%$ of respondents claimed to have used "Tiger Bone Plasters". It is common to find the tiger's image on the package of plasters but the plasters did not list tiger bone as an ingredient because that would be illegal [13]. Since Tiger Bone Plaster was the most frequently used TCM contained tiger bones, and now "Tiger Bone Plaster" no long contains any tiger bone; the number TCM users who actually used tiger bones may be overestimated. Presumably, people were misled by the tiger's image printed on the package. Then, what are the TCM users' perceptions and consumption preferences on these plasters with tiger image on the package?

\section{Materials and Methods}

\section{Sampling method and questionnaire design}

We carried out a questionnaire survey in Beijing in July and August 2014. A stratified random sampling method was adopted to selected citizens who had lived in Beijing for at least 1 year and were over 18 years old [13-15]. First, we investigated that whether the respondents had used "Tiger Bone Plaster" or not; then, we inquired into the users of "Tiger Bone Plaster" whether the plaster they had used had a tiger image on the package. At last, we showed the users the packages of different kinds of "Musk and Bone Strengthening Plaster" brands 
(Supplementary Figure 1) and asked them whether the plasters they had used is "Tiger Bone Plaster", or "Musk and Bone Strengthening Plaster" or something like that. If at the beginning the respondents alleged that they had used "Tiger Bone Plaster", but then they confirmed that the "Plaster" they had used was "Musk and Bone Strengthening Plaster" or something like that, we will ask them why the answers to this question were inconsistent.

\section{Consumption scenarios}

We designed 2 consumption scenarios by adopting stated preference techniques to explore the preferences of respondents $[15,16]$. Before answering the questions, respondents were asked to recall actual past experiences of purchasing or using non-prescription medicine products and imagine that current consumption scenarios were real. After that, the respondents were asked to imagine that they were suffering from a pain and feeling discomfort, thus they might need to buy medicinal plasters for treatment. In scenario 1: there were 8 kinds of "Musk and Bone Strengthening Plasters" available to choose, and 4 of them were packed with tiger images on the packages, and the rest did not have tiger images. In scenario 2: there were 8 kinds of plasters available to choose, and 4 of them named "Musk and Bone Strengthening Plaster", and the rest named "Musk and Tiger Bone Plaster" (Supplementary Figure 1).

\section{Results}

The results showed that a total of $43.78 \%$ respondents (418) alleged that they had used "Tiger Bone Plasters". 97.81\% (179) of the users claimed that they had found a tiger's image printed on the package of "Tiger Bone Plasters" that they had used. In particular, 91.26\% (167) of users confirmed that the "Tiger Bone Plasters" they had used were "Musk and Bone Strengthening Plaster" or other kinds of plasters, rather than "Tiger Bone Plasters". Although only 1.64\% (3) user alleged that the plasters they had used were "Tiger Bone Plaster", they were unsure whether the products used actually contain tiger ingredients. There were few, even no people had really consumed the medicinal plasters which contain tiger bone as ingredient. Theses consumers were misled by the image of tiger on the package. Furthermore, the results showed that there more people would choose plasters printed with tiger images $(0.24 \pm 0.04)$ than those without tiger images $(0.10 \pm 0.03)$ in scenario $1(t=2.553, d f=6, P=0.043<0.05)$, there were no significant differences between the selection frequencies of "Musk and Bone Strengthening Plaster" $(0.20 \pm 0.02)$ and "Musk and Tiger Bone Plaster" $(0.14 \pm 0.03)(t=-1.499, d f=6, P=0.185>0.05)$. People have a preference for plasters with tiger's image because the image made them recall the old "Tiger Bone Plaster", though $61.72 \%$ of the respondents thought that tiger's image was used as a brand symbol.

\section{Discussion}

Tiger's image on the plaster produced a habitual thinking and even a conditional stimulus that tiger image was associated with the "Tiger Bone Plaster". Consumers were misled by the tiger's image printed on the package. Conditional stimuli consist of consumption objects such as brand [17]. More than 40 percent of respondents had used "Musk and Bone Strengthening Plaster" in this study, thus whether the plaster really contained tiger bone or not, consumer will still use the plasters.

Tiger bone was believed to be more effective in ancient tenets of TCM $[4,13,18,19]$. Tiger image is a famous brand; it takes advantage of "brand effect" to use the tiger's image on plasters [13]. The tiger image relieves consumers' memories of "tiger bone", fosters and reinforces a habitual thinking of consumers that the plasters still contain tiger bone as ingredients. Conditional stimulus may consist of a new brand that carry an image belong to a famous brand [17]. For the sake of protecting tigers and deterring consumption motivations that triggered tiger poaching and illegal trade, the manufacturers should remove the tiger image from the "Musk and Bone Strengthening Plaster" and related products according to the regulations of CITES $[6,20]$.

\section{Acknowledgements}

This study was supported by the Knowledge Innovation Project of the Chinese Academy of Sciences (KSCX2-EW-Z-4) and the Natural Science Foundation of China (No. 31372175). We thank all members of the Wildlife and Behavioral Ecology Group, IOZ/CAS and all investigators who participated in the investigation. We are grateful for the recommendations from the members of the expert panel for this project.

\section{References}

1. Dinerstein E, Loucks C, Wikramanayake E, Ginsberg J, Sanderson E, et al. (2007) The fate of wild tigers. BioScience 57: 508-514.

2. IUCN (International Union for Conservation of Nature) (2013) IUCN Red List of Threatened Species. v. 2013.2. IUCN, Gland, Switzerland.

3. Mills J, Jackson P (1994) Killed for a cure: a review of the worldwide trade in tiger bone. TRAFFIC, Cambridge, United Kingdom.

4. Nowell K, Xu L (2007) Taming the tiger trade: China's markets for wild and captive tiger products since the 1993 domestic trade ban. TRAFFIC East Asia, HongKong.

5. Xu L (2008) Illegal trade in Asian big cat products in western China. Pages 4-5 in: Xu HF, Compton J (eds.), The State of Wildlife Trade in China: Information on the trade in wild animals and plants in China 2008. TRAFFIC East Asia, China.

6. CITES (Convention on International Trade in Endangered Species of Wild Fauna and Flora) (2002) Resolution Conference 12.5 (Rev. CoP16): Conservation of and trade in tigers and other Appendix-I Asian big cat species. CITES 12th Meeting of the Conference of the Parties, 03-15 November. CITES, Santiago, Chile.

7. CITES (2007) Summary record of the 13th session of Committee II, 13 June 2007, 13 June 2007. CITES 14th Conference of the Parties, CoP 14 Com. II Rep. 13. CITES, Hague, Netherlands.

8. MHPRC (Ministry of Health of the People's Republic of China) (1993) The notice on changing ingredient and the name of proprietary Chinese medicine which contain rhinoceros horn and tiger bone.

9. SCPRC (State Council of the People's Republic of China) (1993) Notice on the banning the trade of rhinoceros horn and tiger bone. Gazette of the State Council of the People's Republic of China 12: 555-556.

10. Gratwicke B, Bennett E, Broad S, Christie S, Dutton A, et al. (2008) The world can't have wild tigers and eat them, too. Conservation Biology 22: 222-223.

11. Guo YF, Zou XY (1997) Investigation report on sustainable utilization of medical animal. Pages 257-278 in: China Council for International Cooperation on Environment and Development (ed.), Biodiversity Protection in China. China Environmental Science Press, Beijing.

12. CWCA (China Wildlife Conservation Association) (2011) Investigation Report on Illegal Trade of Endangered Species of Wild Fauna and Flora and Its Products. CWCA, Beijing, China

13. Gratwicke B, Mills J, Dutton A, Gabriel G, Long B, et al. (2008) Attitudes toward consumption and conservation of tigers in China. PLOS ONE 3:e2544.

14. Kish L (1987) Statistical Design for Research. John Wiley and Sons, New York. 
Citation: Liu Z, Jiang Z (2015) Tiger Image on Medicinal Plasters Serve as a Cue for Traditional Medicine Consumers. J Biodivers Endanger Species 3: 142. doi:10.4172/2332-2543.1000142

Page 3 of 3

15. Dutton AJ, Hepburn C, Macdonald DW (2011) A stated preference investigation into the Chinese demand for formed vs. wild bear bile. PLOS ONE 6: e21243.

16. Pearmain D, Swanson J, Kroes E, Bradley M (1991) Stated Preference Techniques: A Guide to Practice. 2nd ed. Steer Davies Gleave \& Hague Consulting Group, London.

17. Schiffman LG, Kanuk LL (2004) Consumer Behavior. 8th ed. Pearson Prentice Hall, Upper Saddle River, New Jersey.

18. CCMA (Cooperative group of Chinese medicinal animal records) (1979) Chinese Medicinal Animal Records. Tianjing Science \& Technology Press, Tianjing, China.
19. Ma YQ (1979) Siberian tigers in China. Chinese Journal of Wildlife 1: 23-26.

20. SAIC (State Administration for Industry and Commerce) (1993) The notice on strengthening the wildlife protection and enforcing laws against the trade and promotion of endangered species and products made of them. 